\title{
A Study on Circular Economy Material Using Fish Scales as Natural Flame Retardant and the Properties of Its Composite Materials
}

\author{
Shang-Hao Liu ${ }^{1}$, Ming-Yuan Shen ${ }^{2 *}$, Cheng-You Yang ${ }^{3}$ and Chin-Lung Chiang ${ }^{3, * *}$ \\ 1 Department of Ammunition Engineering and Explosion Technology, Anhui University of Science and \\ Technology, Huainan 232001, Anhui, China; u9414042@cmu.edu.tw \\ 2 Department of Mechanical Engineering, National Chin-Yi University of Technology, Taichung City 41170, \\ Taiwan; hbj678@gmail.com \\ 3 Green Flame Retardant Material Research Laboratory, Department of Safety, Health and Environmental \\ Engineering, Hung-Kuang University, Taichung 433, Taiwan; willian2546jane@gmail.com(C.Y. Yang); \\ dragon@sunrise.hk.edu.tw(C.L.Chiang) \\ * Correspondence: hbj678@gmail.com; Tel.: +886-4-23924505 \\ ** Correspondence: dragon@sunrise.hk.edu.tw; Tel.: +886-4-2631-8652-4008
}

\begin{abstract}
In this study, a composite flame retardant was created by combining fish scale (FS), fishery waste, and ammonium polyphosphate (APP), a commercially available flame retardant. The composite flame retardant was added to epoxy resin (EP) to form an EP/APP/FS composite that prevents burns and is environmentally friendly. The use of FS conforms to the concept of circular economy and lowers costs by reducing the consumption of APP. Thermogravimetric analysis (TGA), integral procedural decomposition temperature (IPDT), pyrolysis kinetics, limiting oxygen index (LOI), the Underwriters Laboratories 94 (UL94) flammability test, scanning election microscopy, Raman spectroscopy, and energy-dispersive X-ray spectroscopy were used to determine the thermal properties, flame retardant properties, flame retardant mechanism, char morphology, and composition of the composites. The TGA results indicated that the addition of $40 \%$ flame retardant raised the char residue from $16.45 \mathrm{wt} \%$ (pure EP) to $36.07 \mathrm{wt} \%$, IPDT from $685.6^{\circ} \mathrm{C}$ (pure EP) to $1143.1^{\circ} \mathrm{C}$, LOI from $21 \%$ (pure EP) to $30 \%$, and UL94 classification from fail (pure EP) to V-0. These results suggest an increase in char residue, which indicates better protection of the polymer matrix material. The improvements in IPDT, LOI, and UL94 classification, which indicate greater thermal stability, lower flammability (from flammable to fireproof), and higher flammability rating (from fail to V-0), respectively, suggest that the composite material has favorable thermal properties and is less inflammable.
\end{abstract}

Keywords: fishery waste $、$ epoxy $、$ fish scale $、$ ammonium polyphosphate $、$ flame retardant

\section{Introduction}

Epoxy resin (EP) has been used in various fields, such as aeronautics, chemistry, civil engineering, automobiles, recreation, electronics, and shipbuilding. It is used as a material for circuit boards, movable parts, coatings, and numerous other applications because of its excellent insulating and chemical-resistant properties as well as its minimal cure shrinkage. However, EP has problems such as high flammability, low impact resistance, and poor weather resistance, which prevent it from having a wider range of applications [1-4].

$\mathrm{EP}$ is highly flammable, and when it burns, it releases a large amount of smoke and volatile gases. Thus, the presence of EP in a fire can make egress difficult and lead to serious casualties. For this reason, this study proposed introducing a composite fish scale (FS)-phosphorus flame retardant to make EP less inflammable. 
FS was chosen as an additive because Taiwan is an island surrounded by sea with a prosperous fishing industry but has little use for FS. Most of the FSs removed from fish are discarded, and only a small portion are used for compost, collagen extraction, and corneal cell culture. FS consists of collagen and hydroxyapatite $\left(\mathrm{Ca}_{5}\left(\mathrm{PO}_{4}\right)_{3}\right)$. Hydroxyapatite contains phosphorus and calcium elements, which accelerate the formation of a char layer and increase char yield (CY). Collagen contains nitrogen, which releases a large amount of nonflammable gas when burnt that lowers the concentration of oxygen in the air. These properties allow FS to effectively reduce the inflammability of a material, so it is one kind of natural flame retardant [5-8].

This study developed a composite material that combines EP with a flame retardant to reduce the inflammability of EP. The flame retardant consists of a flame retardant agent, ammonium polyphosphate (APP), which contains highly incombustible phosphorus and nitrogen, and FS. The composite material was tested using thermogravimetric analysis (TGA), limiting oxygen index (LOI), the Underwriters Laboratories 94 (UL94) flammability test, scanning election microscopy (SEM), and Raman spectroscopy to determine its thermal properties, flame retardant properties, flame retardant mechanism, and morphology.

\section{Experimental}

\subsection{Materials}

DGEBA-type epoxy was kindly supplied by Nan-Ya Plastics Corporation, Taipei City, Taiwan. 4, 4'-Diaminodiphenylmethane (DDM) as a curing agent for epoxy and ammonium polyphosphate (APP) was purchased from San-Jin Chemicals Co. Kaohsiung, Taiwan. Fish scales (FS) were obtained from the local market. Anhydrous stabilized tetrahydrofuran (THF) was obtained from Lancaster Co., Morecambe, Lancashire, UK

\subsection{Preparation of Epoxy/APP/FS composites}

The FSs were sieved, cleansed with fresh water, and ultrasonicated to remove foreign matter. Subsequently, they were baked at $105^{\circ} \mathrm{C}$ for $4 \mathrm{~h}$ and shredded into powder. After the FS powder was prepared, $2.83 \mathrm{~g}$ of APP and $5.67 \mathrm{~g}$ of FS at a weight ratio of 1:2 were added to $60 \mathrm{~mL}$ of tetrahydrofuran and evenly mixed at $60{ }^{\circ} \mathrm{C}$ for $2.5 \mathrm{~h}$. Then, $10 \mathrm{~g}$ of EP was evenly mixed into the APP/FS composite flame retardant, and $2.75 \mathrm{~g}$ of diaminodiphenylmethane (curing agent) was stirred into the mixture until it thickened, at which point the mixture was poured into a mold and left to set overnight. The next day, it was baked at 60 to $160{ }^{\circ} \mathrm{C}$ at increasing intervals of $20{ }^{\circ} \mathrm{C}$ every $2 \mathrm{~h}$ to complete the preparation of the EP/APP/FS composites.

\subsection{Measurements}

The samples were treated at $180^{\circ} \mathrm{C}$ for $2 \mathrm{~h}$ and then ground into a fine powder. The thermal degradation of the composite was examined using a thermogravimetric analyzer (TGA) (Perkin Elmer TGA 7) from room temperature to $800{ }^{\circ} \mathrm{C}$ at a rate of $10{ }^{\circ} \mathrm{C}$ min-1 under an atmosphere of nitrogen. The measurements were made on 6-10 mg samples. Mass-loss/temperature curves were plotted. The LOI is defined as the minimum fraction of $\mathrm{O} 2$ in a mixture of $\mathrm{O} 2$ and $\mathrm{N} 2$ that will just support faming combustion. The LOI test was performed according to the testing procedure of the ASTM D 2836 Oxygen Index Method, with a test specimen bar $7-15 \mathrm{~cm}$ long, $6.5 \pm 0.5 \mathrm{~mm}$ wide, and $3.0 \pm 0.5 \mathrm{~mm}$ thick. The sample bars were suspended vertically and ignited by a Bunsen burner. The fame was removed and the timer was started. The concentration of oxygen was increased if the fame on the specimen was extinguished before burning for 3 min or burning away $5 \mathrm{~cm}$ of the bar. The oxygen content was adjusted until the limiting concentration was determined. The vertical burning test was done inside a fume hood. Samples were held ver- 
tically with tongs at one end and burned from the free end. Samples were exposed to an ignition source for $10 \mathrm{~s}$ then they were allowed to burn above cotton wool until both sample and cotton wool extinguished. Observable parameters were recorded to assess fire retardancy. The UL 94 test classifies the materials as V-0, V-1, and V-2 according to the time period needed before self-extinction and the occurrence of flaming dripping after removing the ignition source. $\mathrm{V}-0$ is the most ambitious and desired classification. The morphology of the fractured surface of the composites was studied under a scanning electron microscope (SEM) (JEOL JSM 840A, Japan). The distributions of Si atoms in the char were obtained from SEM EDX mapping (JEOL JSM 840A, Japan). Raman spectra were recorded using a Lab Ram I confocal Raman spectrometer (Dilor, France). An He-Ne laser with a laser power of about $15 \mathrm{~mW}$ at the sample surface was (used OR utilized) to provide an excitation wavelength of $632.8 \mathrm{~nm}$. A holographic notch filter reflected the exciting line into an Olympus BX40 microscope, Tokyo, Japan.

\section{Results and discussion}

\subsection{Thermal properties}

\subsubsection{TGA}

TGA involves the use of a microbalancer to record a specimen's mass loss with temperature and determine the material's thermal stability. In TGA, different amounts of the APP/FS flame retardant are introduced to EP under a nitrogen environment at a heating rate of $20^{\circ} \mathrm{C} / \mathrm{min}$ to observe the mass loss of the mixture with temperature. Figure 1, Figure 2, and Table 1 present the results.

As shown in Figure 1, the temperature at $5 \%$ mass loss ( $\mathrm{T} d \mathrm{~d}$ ) decreased considerably, from $397.1{ }^{\circ} \mathrm{C}$ (pristine EP) to $238.5{ }^{\circ} \mathrm{C}$ (EP/FS/APP $40 \%$ ). Likewise, char yield rose from 16.45 wt. \% (pure EP) to $36.07 \mathrm{wt}$. \% (EP/FS/APP $40 \%$ ). This result can be explained by the presence of phosphorus in the flame retardant, which caused the material to break down at a lower temperature. This process contributed to the formation of a char layer that insulated the inner part of the specimen from heat, thus protecting the EP and increasing the overall thermal stability of the material [9-10].

Figure 2 presents the derivative thermogravimetric (DTG) curves, which demonstrate the trends of the materials reaching their maximum thermal degradation temperatures with time and temperature. According to Figure 2, the maximum thermal degradation temperature decreased from $432.7^{\circ} \mathrm{C}$ (pure EP) to $376.9^{\circ} \mathrm{C}$ (EP/FS/APP $40 \%$ ). This result can be explained by the presence of phosphorus in the flame retardant, which caused the material to break down at a lower temperature, contributing to the formation of a protective char layer. The maximum thermal degradation rate decreased considerably, from $-24.5 \mathrm{wt} . \% / \mathrm{min}$ (pristine EP) to $-13.9 \mathrm{wt} . \% / \mathrm{min}$ (EP/FS/APP $40 \%$ ), indicating a substantial improvement in EP's thermal stability after the addition of the composite flame retardant.

Table 1 indicates that $T_{\mathrm{d} 5}$ shifted leftward, the thermal degradation rate decreased, and $\mathrm{CY}$ increased substantially with the increase in flame retardant. This result can be attributed to the presence of phosphorus, which induced the formation of phosphorus-containing char at a lower temperature, thereby protecting the matrix material. Hence, the composite flame retardant can effectively improve the thermal stability of polymeric composite materials. 


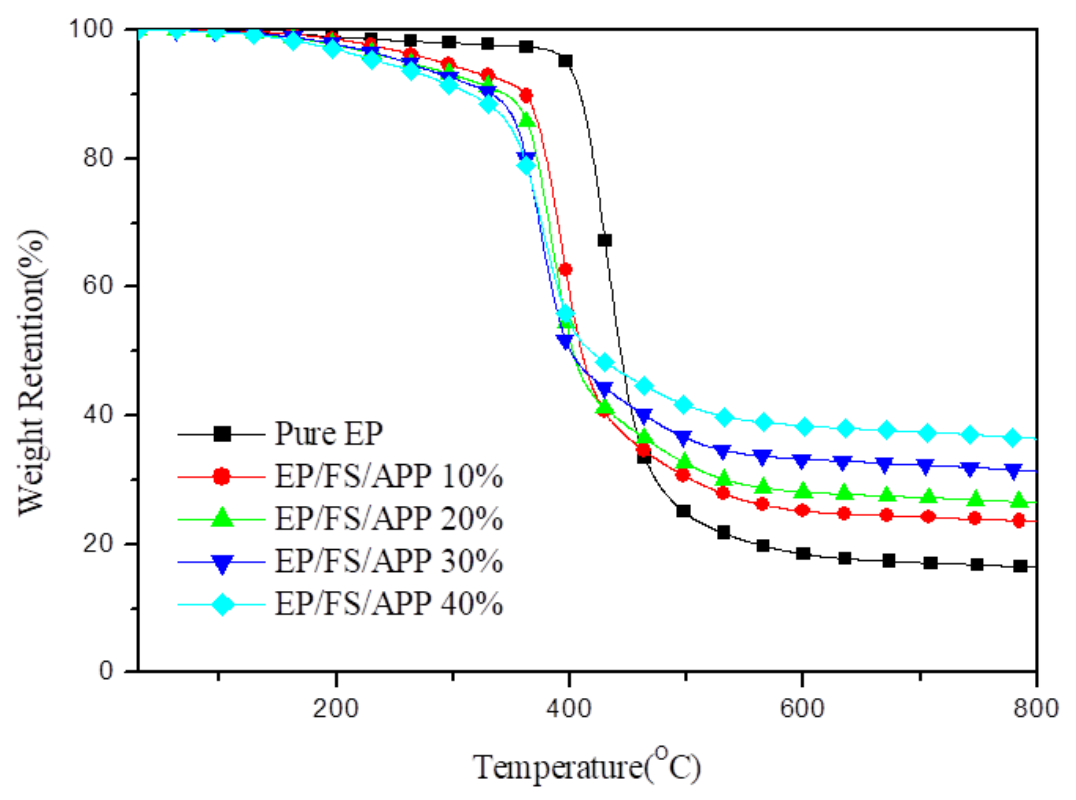

Figure 1 TGA curves of Epoxy and Epoxy/APP/FS composites in N2.

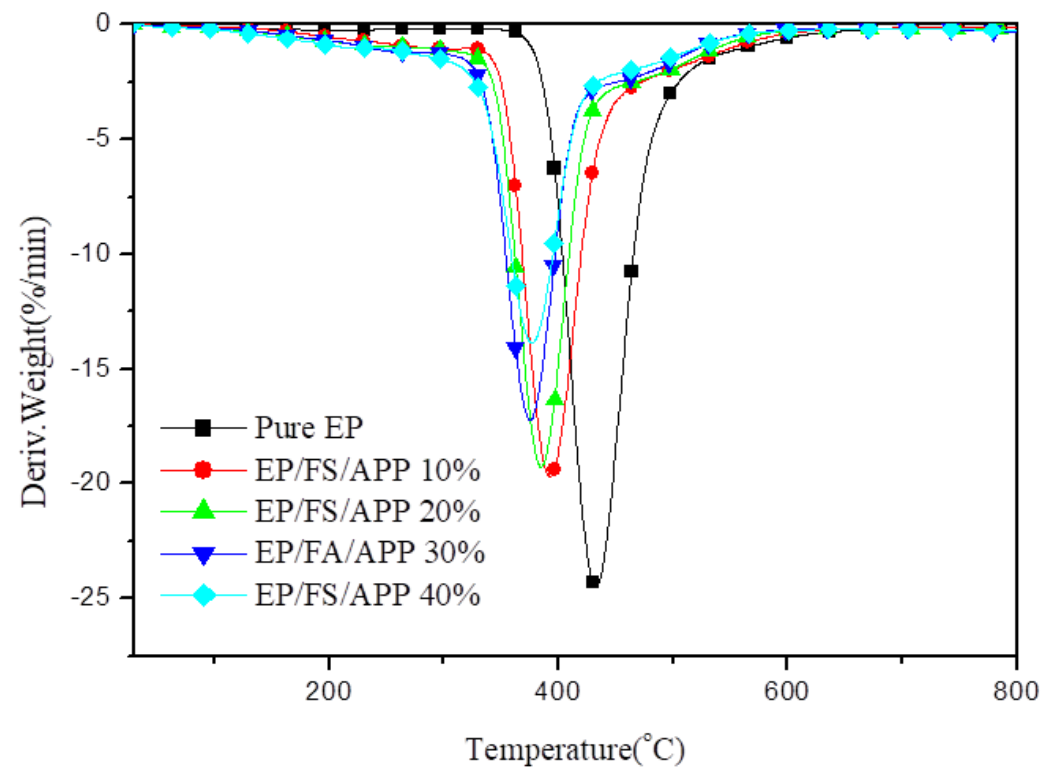

Figure 2 Derivative curves of pure Epoxy and Epoxy/APP/FS composites in $\mathrm{N}_{2}$. 
Table 1 Thermal properties of Epoxy/APP/FS composites

\begin{tabular}{|c|c|c|c|c|c|}
\hline Sample NO. & ${ }^{\mathrm{a}} \mathrm{T}_{\mathrm{d} 5}\left({ }^{\circ} \mathrm{C}\right)$ & ${ }^{\mathrm{b}} \mathrm{T}_{\max }\left({ }^{\circ} \mathrm{C}\right)$ & ${ }^{\mathrm{c}} \mathrm{R}_{\max }(\mathrm{wt} \% / \mathrm{min})$ & $\operatorname{IPDT}\left({ }^{\circ} \mathrm{C}\right)$ & C.Y $(w t \%)$ \\
\hline pure epoxy & 397.1 & 432.7 & -24.5 & 685.6 & 16.45 \\
\hline EP/APP/FS $10 \%$ & 288.7 & 392.4 & -19.6 & 802.7 & 23.56 \\
\hline EP/APP/FS $20 \%$ & 260.4 & 384.9 & -19.3 & 866.1 & 26.44 \\
\hline EP/APP/FS $30 \%$ & 258 & 378.7 & -17.2 & 980.4 & 30.80 \\
\hline EP/APP/FS $40 \%$ & 238.5 & 376.9 & -13.9 & 1143.1 & 36.07 \\
\hline
\end{tabular}

${ }^{a} \mathrm{~T}_{\mathrm{d} 5}$ is the temperature when the weight loss of sample reaches its $5 \%$.

${ }^{\mathrm{b}} \mathrm{T}_{\max }$ corresponds to the temperature of the maximum degradation rate.

${ }^{c} R_{\max }$ corresponds to the maximum thermal degradation rate.

\subsection{Subsection}

\subsubsection{IPDT [11-12]}

Integral procedural decomposition temperature (IPDT) is mainly used as an indicator of the thermal stability of polymeric materials. IPDT can be obtained by integrating the area under the thermal decomposition curve and substituting it into an integration equation. A high IPDT indicates favorable thermal stability. IPDT can be affected by initial thermal decomposition temperature and CY, which are also used as indicators of thermal stability. High initial thermal decomposition temperature and CY indicate high thermal stability and heat resistance and therefore high IPDT. IPDT can be calculated by substituting Ti, Tf, S1, S2, and S3 into the following equations: 


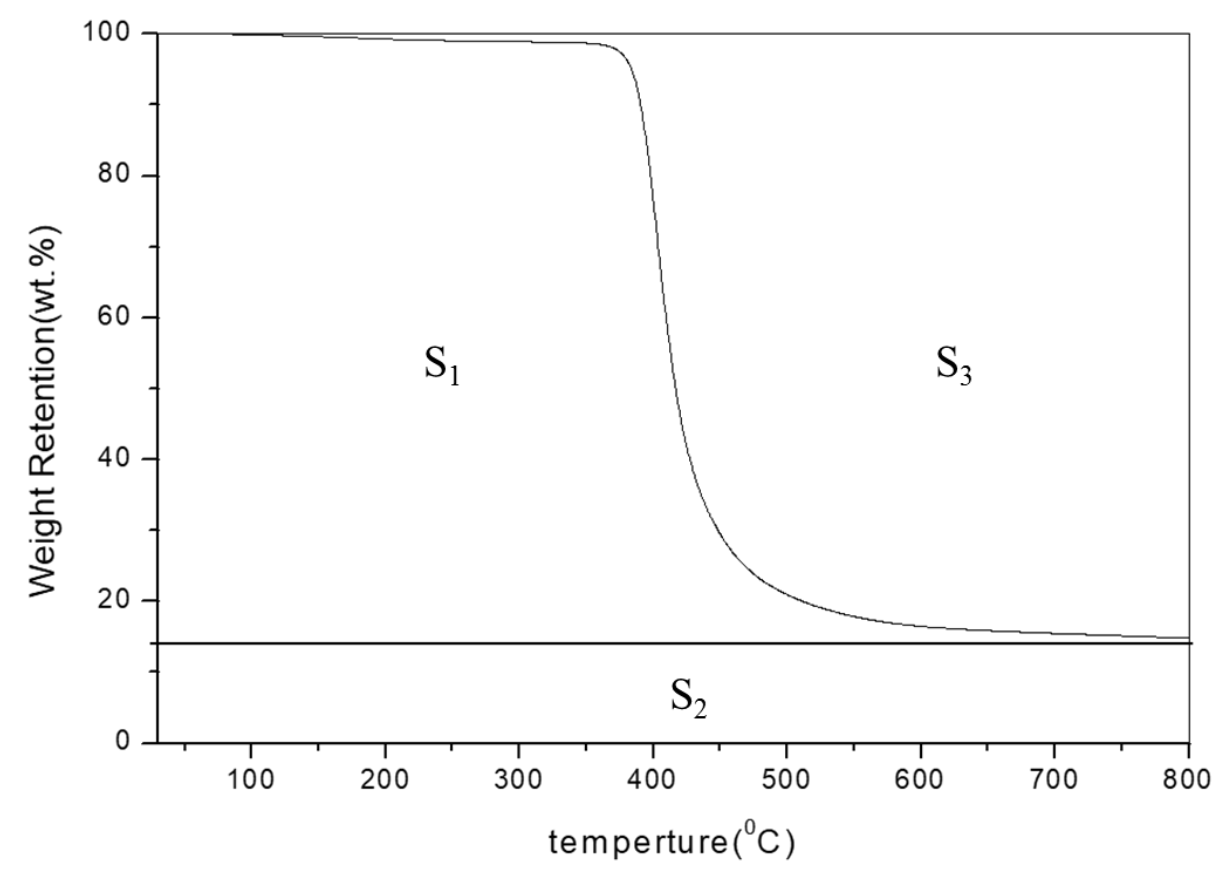

Figure 3 The TGA curve of the sample

$\operatorname{IPDT}\left({ }^{\circ} \mathrm{C}\right)=\mathrm{A}^{*} \times \mathrm{K}^{*} \times\left(\mathrm{T}_{\mathrm{f}}-\mathrm{T}_{\mathrm{i}}\right)+\mathrm{T}_{\mathrm{i}}$

$A^{*}=\left(S_{1}+S_{2}\right) /\left(S_{1}+S_{2}+S_{3}\right)$

$K^{*}=\left(S_{1}+S_{2}\right) / S_{1}$

$\mathrm{T}_{\mathrm{i}}=$ the initial experimental temperature $\left(30^{\circ} \mathrm{C}\right)$

$\mathrm{T}_{\mathrm{f}}=$ the final experimental temperature $\left(800^{\circ} \mathrm{C}\right)$

Table 1 presents the IPDTs of the EP/APP/FS composites. These IPDTs are $685.6{ }^{\circ} \mathrm{C}$ (pristine EP), $802.7^{\circ} \mathrm{C}(\mathrm{EP} / \mathrm{APP} / \mathrm{FS} 10 \%), 866.1^{\circ} \mathrm{C}(\mathrm{EP} / \mathrm{APP} / \mathrm{FS} 20 \%), 980.4^{\circ} \mathrm{C}(\mathrm{EP} / \mathrm{APP} / \mathrm{FS}$ $30 \%)$, and $1143.1{ }^{\circ} \mathrm{C}(\mathrm{EP} / \mathrm{APP} / \mathrm{FS} 40 \%)$. The EP/APP/FS composites had IPDTs higher than that of pristine EP, confirming that the addition of the flame retardant improved the thermal stability of EP. The data in Table 1 and Figure 4 also support the TGA results.

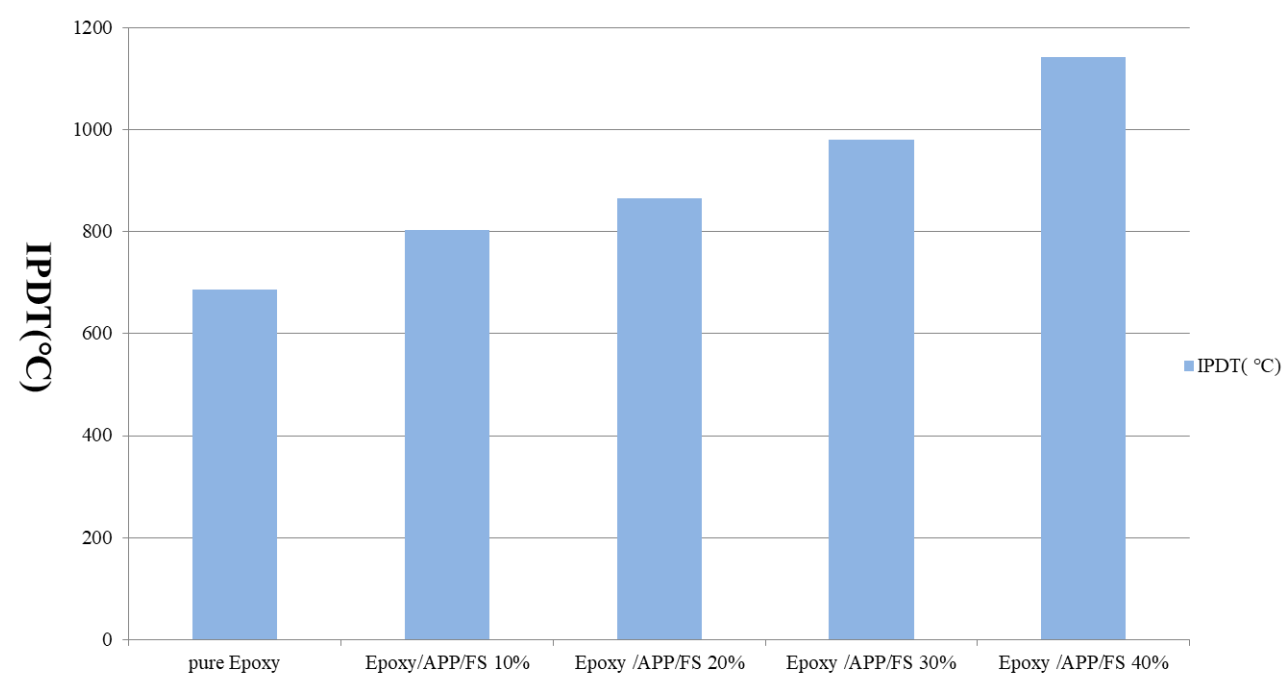

Figure 4 The IPDT data of pure Epoxy and Epoxy /APP/FS composites. 


\subsubsection{Kinetics of thermal degradation using Ozawa's method}

The combustion of a polymeric material involves burning of the material with oxygen and the eventual formation of char residue and gas. However, before the polymeric material can begin to burn, an energy barrier must be overcome for the material to enter the thermal decomposition process. This energy barrier is the activation energy required for thermal decomposition. In this study, Ozawa's method [13] was adopted to calculate the activation energy, the results of which are presented in Table 2 . The $\mathrm{R}$ values of both pure EP and EP/APP/FS 40\% exceeded 0.9, indicating excellent linearity. The activation energy of pure EP and EP/AP/FS $40 \%$ was $217 \mathrm{~kJ} / \mathrm{mole}$ and $230 \mathrm{~kJ} / \mathrm{mole}$, respectively, suggesting that the addition of the flame retardant increased the activation energy required by the EP/APP/FS composites and improved their thermal stability. These results also support the TGA results.

Table 2 The calculated activation energy of thermal degradation with various conversions by Ozawa's method.

\begin{tabular}{|c|c|c|c|c|}
\hline \multirow{2}{*}{$\alpha$} & \multicolumn{2}{|c|}{ Epoxy } & \multicolumn{2}{|c|}{ Epoxy/APP/FS 40\% } \\
\hline & $\mathrm{E}(\mathrm{kJ} / \mathrm{mole})$ & R Value & $\mathrm{E}(\mathrm{kJ} / \mathrm{mole})$ & R Value \\
\hline 0.1 & 241 & 0.935 & 93 & 0.901 \\
\hline 0.2 & 230 & 0.966 & 202 & 0.938 \\
\hline 0.3 & 216 & 0.984 & 242 & 0.920 \\
\hline 0.4 & 195 & 0.992 & 228 & 0.951 \\
\hline 0.5 & 183 & 0.998 & 202 & 0.974 \\
\hline 0.6 & 184 & 0.999 & 186 & 0.985 \\
\hline 0.7 & 188 & 0.999 & 200 & 0.996 \\
\hline 0.8 & 218 & 0.999 & 419 & 0.993 \\
\hline 0.9 & 299 & 0.990 & 304 & 0.989 \\
\hline$\Delta \mathrm{E}(\mathrm{av})$ & 217 & & 230 & \\
\hline
\end{tabular}

\subsection{Flame retardant property}

\subsubsection{UL-94}

The UL94 flammability test involves the ignition of specimens of a specific size, whose burning durations are added to determine whether a material meets the UL94 standard and whether melt-dripping occurred (evidenced by a cotton layer beneath the specimen being ignited by drips of molten material). On the basis of the test results, the flammability is rated as V-0, V-1, V-2, or fail. [14-15]

A specimen is burnt for $10 \mathrm{sec}$, after which the heat source is removed. The time from the removal of the heat source until the burning stops is recorded $\left(\mathrm{t}_{1}\right)$. Subsequently, the specimen is burnt again for $10 \mathrm{sec}$, and the time from the removal of the heat source until the burning stops is also recorded $\left(\mathrm{t}_{2}\right)$.

$\mathrm{V}-0$ : If $\mathrm{t}_{1}+\mathrm{t}_{2}<10 \mathrm{sec}$ and no melt-dripping occurred, it is classified as $\mathrm{V}-0$ rating.

$\mathrm{V}-1$ : If $\mathrm{t}_{1}+\mathrm{t}_{2}<30$ sec and no melt-dripping occurred, it is classified as V-1 rating. 
$\mathrm{V}$-2: If $\mathrm{t}_{1}+\mathrm{t}_{2}<30$ sec and melt-dripping occurred, it is classified as $\mathrm{V}-2$ rating.

Fail: If $\mathrm{t}_{1}+\mathrm{t}_{2}>30 \mathrm{sec}$, it is classified as fail rating.

As shown in Table 3, pristine EP was classified as fail, whereas the addition of the composite flame retardant resulted in EP/APP/FS $40 \%$ being classified as V-0 rating. This result indicates that adding the flame retardant can effectively make a matrix material more difficult to burn, causing by phosphorus-containing fish scales and APP promote the formation of char and prevent the polymer matrix further degradate

Table 3 The flame retardance of Epoxy/APP/FS composites by UL-94 and LOI values.

\begin{tabular}{|c|c|c|c|c|}
\hline \multirow{2}{*}{ Sample } & \multicolumn{2}{|c|}{ UL-94 } & \multirow{2}{*}{ LOI } & \multirow{2}{*}{$\Delta \mathrm{LOI}$} \\
\hline & Ranking & Dripping & & \\
\hline pure Epoxy & Fail & NO & 21 & 0 \\
\hline EP/APP/FS $10 \%$ & Fail & $\mathrm{NO}$ & 21 & 0 \\
\hline EP/APP/FS $20 \%$ & Fail & NO & 23 & 2 \\
\hline EP/APP/FS $30 \%$ & $\mathrm{~V}-0$ & NO & 27 & 6 \\
\hline EP/APP/FS $40 \%$ & $\mathrm{~V}-0$ & $\mathrm{NO}$ & 36 & 15 \\
\hline
\end{tabular}

\subsubsection{LOI}

LOI is widely used to test the flammability of the materials through various oxygen concentrations. LOI involves increasing or decreasing the oxygen content of a confined space to determine the flammability of a material. The concentration of oxygen in the atmosphere is approximately 21\%. A material can be classified as flammable, self-extinguishing, or fireproof depending on the test standards. [16-17]

Flammable: LOI $<21 \%$

Self-extinguishing: $22 \%<$ LOI $<25 \%$

Fireproof: $\mathrm{LOI}>26 \%$

LOI is calculated by using the following equation, where $\mathrm{O} 2$ and $\mathrm{N} 2$ represent the flow rates $(\mathrm{mL} / \mathrm{sec})$ of oxygen and nitrogen, respectively:

$$
\mathrm{LOI}=\frac{\mathrm{O}_{2}}{\mathrm{O}_{2}+\mathrm{N}_{2}} \times 100(\%)
$$

According to the results of the test, pristine EP had an LOI of $21 \%$, marking it as a flammable polymer. After the addition of flame retardant, however, the LOI of the $\mathrm{EP} / \mathrm{APP} / \mathrm{FS} 40 \%$ composite reached $36 \%$, a $15 \%$ increase, suggesting that the composite had become a fireproof material in Table 3. This result can be attributed to the presence of the phosphorus-based flame retardant, which quickly formed a char layer under high temperatures that protected the polymer matrix (EP) from further decomposition.

As shown in Table 4 and Figure 5, the amount of flame retardant was fixed at 40 $\mathrm{wt} \%$, and the proportions of FS and APP were changed to determine the synergy between the two components. When only one component was used in the flame retardant, the LOIs of the resultant composites were $46 \%$ (EP/APP) and $23 \%$ (EP/FS). When the ratio of FS:APP was 1:2 and 2:1, the LOIs were $47 \%$ and $36 \%$, respectively. Figure 6 shows that when the FS:APP ratio was 1:2, the difference between the experimental and theoretical (calculated) LOI was 8.7, and when the FS:APP ratio was 2:1, the difference was 5.4. Thus, the experimental value was greater than the theoretical value in both cases, indicating that the commercial fire retardant and natural fire retardant synergize with each other. An FS: APP ratio of 2:1 was selected as the recommended ratio because of cost considerations in this study. 
Table 4 Comparison of calculated and experimental LOI data of the composites

\begin{tabular}{c|cc}
\hline Sample No. & FS:APP & LOI \\
\hline $\begin{array}{c}\text { EP/APP 40\% } \\
\text { (experimental) }\end{array}$ & $0: 3$ & 46 \\
EP/APP 40\% & $1: 2$ & 47 \\
(experimental) & & 36 \\
EP/APP/FS 40\% & $2: 1$ & \\
(experimental) & & 23 \\
EP/FS 40\% & $3: 0$ & \\
(experimental) & & 38.3 \\
EP/APP/FS 40\% & $1: 2$ & 30.6 \\
(calculated) & & \\
EP/APP/FS 40\% & $2: 1$ & \\
(calculated) & & \\
\hline
\end{tabular}

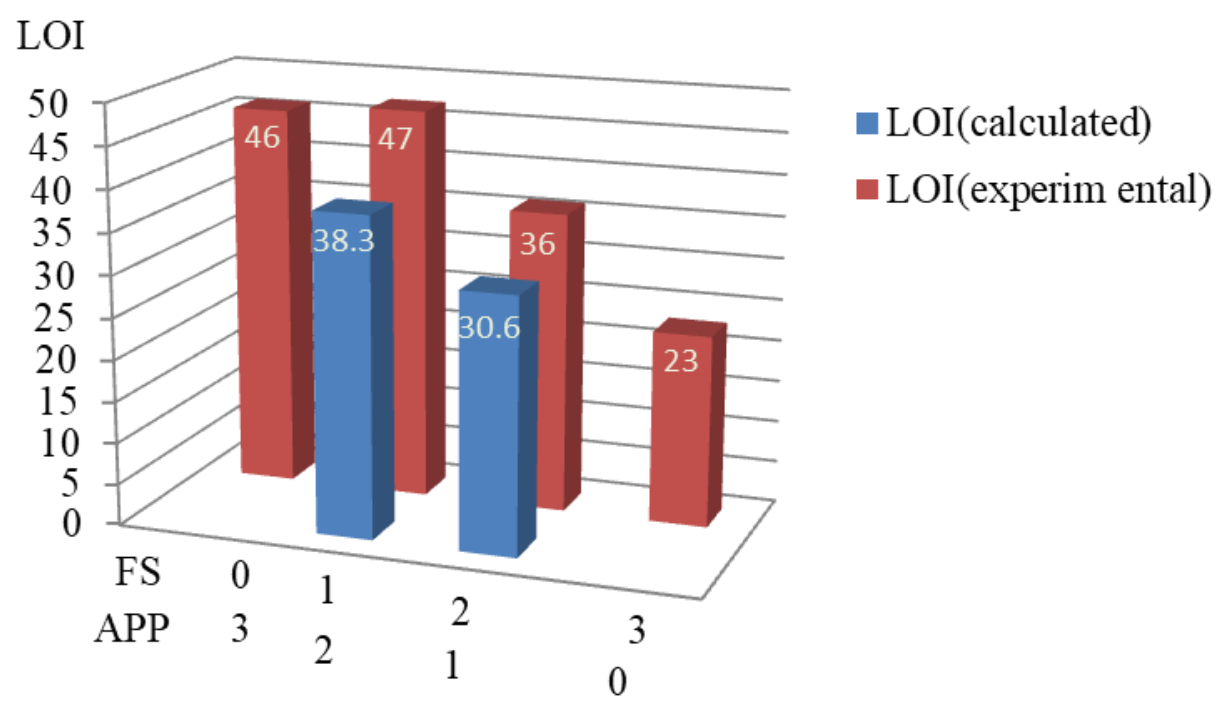

Figure 5 Comparison of calculated and experimental LOI of the composites

\subsection{Morphological properties}

\subsubsection{SEM}

SEM involves using a beam of electrons to scan a specimen in a vacuum chamber, in which the specimen's electrons are excited by the beam and detected by a scan coil, which generates signals that are converted into images and displayed on a screen. SEM enables the observation of a material's morphological properties, including its surface 
structure, grain size, and other morphological phenomena that occur on the surface, such as surface nucleation. [18]

Figure 6(a) and (c) presents the surface of pure EP and EP/APP/FS $40 \%$ before burning. In Figure 6(a), the particles visible on the surface are grains of APP/FS that were added. In Figure 6(c), the presence of numerous particles and the irregular surface structure are the result of the addition of a large amount of flame retardant. Figure 6(b) presents EP/APP/FS 10\% after burning. A light layer of char was observed, and the holes and pits were formed by the gas released by APP when burning. These holes and pits compromised the protection on the polymer matrix material because they allow flame to pass through and reach the base material. For this reason, the performance of this composite was deemed unsatisfactory. Figure 6(d) presents EP/APP/FS 40\% after burning. A dense char layer on the surface barred the transmission of oxygen and heat, thereby raising the thermal stability of the composite.
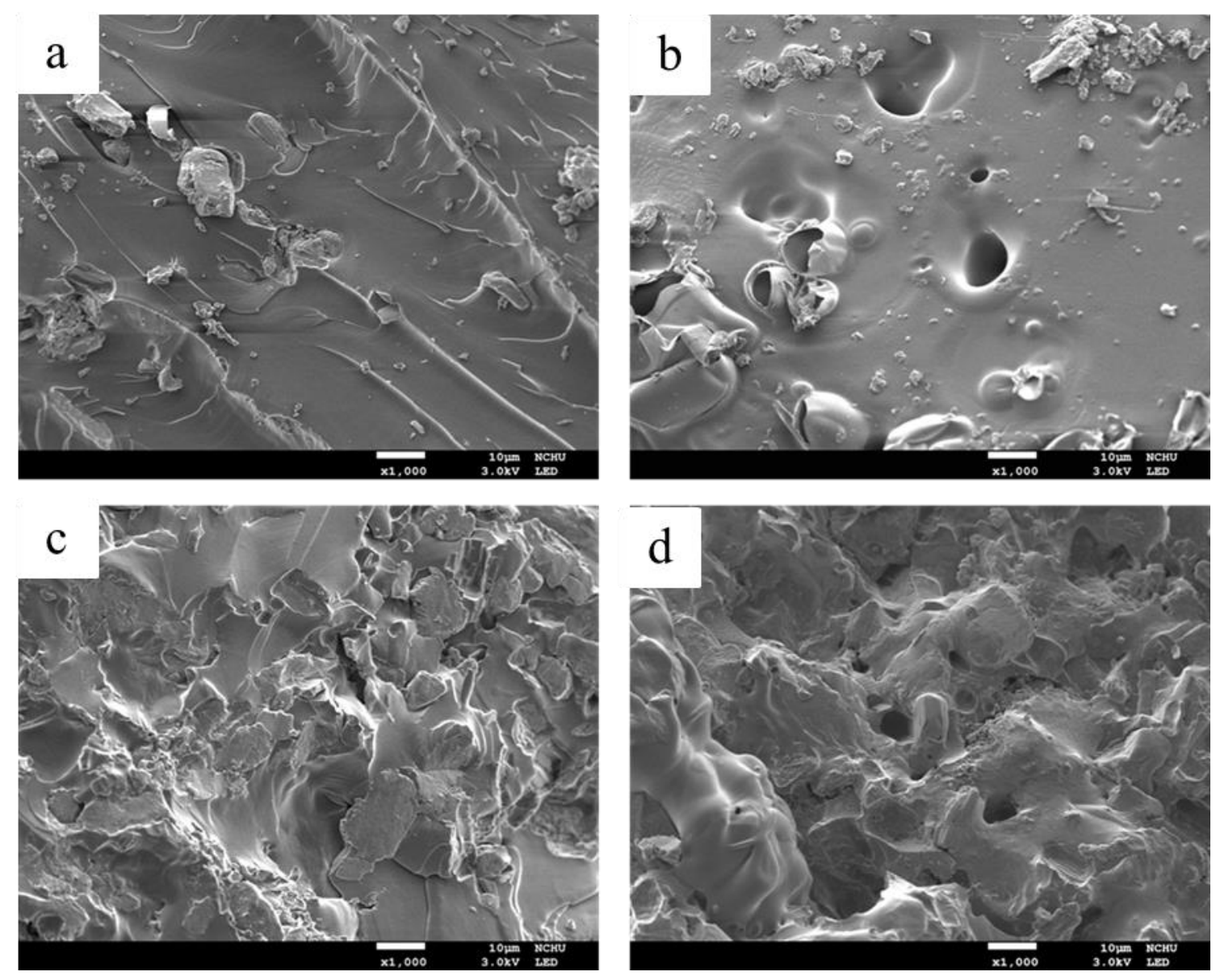

Figure 6 SEM micrographs of composites (a) Epoxy/APP/FS 10\%(before burning)(×1K) (b) Epoxy/APP/FS 10\%(after burning)( $\times 1 \mathrm{~K})$ (c) Epoxy/APP/FS 40\%(before burning)(×1K) (d) Epoxy/APP/FS 40\%(after burning)(×1K).

\subsubsection{EDS}

In energy-dispersive X-ray spectroscopy (EDS), an electron in an inner electron shell of an atom is excited by an external energy source (e.g., an electron beam) and leaves the atom. This causes an electron in an outer, high-energy shell to migrate to the vacancy left by the escaped electron, causing excessive energy to be released. The energy, which is the difference in energy levels between the two shells, is either released in the form of X-rays or excites another electron in an outer shell to leave the atom. Because each element has its distinct energy level, analyzing the X-rays released enables the elemental composition of a specimen to be identified, which in turn indicates the composition of the specimen's surface material. 
Figure 7 and Table 6 present the EDS results of the EP/APP/FS composites containing different proportions of the APP/FS flame retardant. Before being burned, EP/APP/FS $10 \%$ contained C, O, N, P, and Ca with weight percentages of $66.3 \mathrm{wt} \%$, 13.08 wt. $\%, 19.62$ wt. $\%, 0.66$ wt. $\%$, and 0.35 wt. $\%$, respectively. After raising the flame retardant to $40 \%$, the contents of N, P, and Ca in EP/APP/FS 40\% increased. This was caused by the addition of the flame retardant, which contained these elements. Specifically, P increased from 0.66 wt.\% to $2.61 \mathrm{wt} \%$, and Ca rose from 0.35 wt.\% to1.45 wt.\%. When burned, the P in $\mathrm{EP} / \mathrm{APP} / \mathrm{FS} 40 \%$ dehydrated the material, forming a phosphate-based char layer that raised the weight percentage of $\mathrm{P}$ to $12.13 \mathrm{wt}$. \% after the material was burned. This indicates that in the burning process, the presence of $\mathrm{P}$ increases $\mathrm{CY}$, thereby facilitating the formation of a char layer that covers the surface of the matrix material and prevents it from being burned further.

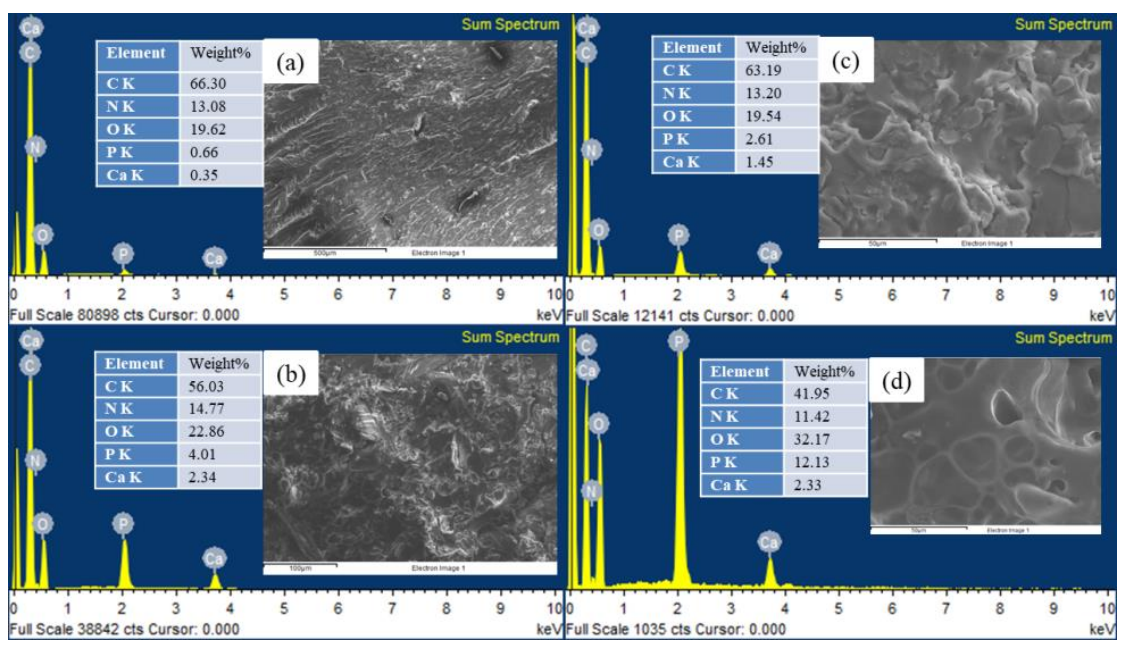

Figure 7 EDS of (a) Epoxy/APP/FS 10\% (before burning) (b) Epoxy/APP/FS 10\% (after burning) (c) Epoxy/APP/FS 40\% (before burning) (d) Epoxy/APP/FS 40\% (after burning).

Table 6 EDS for Epoxy/APP/FS composites.

\begin{tabular}{|c|c|c|c|c|c|}
\hline \multirow{2}{*}{ Sample No. } & \multicolumn{5}{|c|}{ Elements } \\
\hline & $\mathrm{C}(\mathrm{wt} . \%)$ & $\mathrm{N}($ wt. \%) & $\mathrm{O}($ wt. $\%)$ & $\mathrm{P}(\mathrm{wt} . \%)$ & $\mathrm{Ca}($ wt.\%) \\
\hline $\begin{array}{l}\text { EP/APP/FS } 10 \% \\
\text { (before burning) }\end{array}$ & 66.3 & 13.08 & 19.62 & 0.66 & 0.35 \\
\hline $\begin{array}{c}\text { EP/APP/FS } 10 \% \\
\text { (after burning) }\end{array}$ & 56.03 & 14.77 & 22.86 & 4.01 & 2.34 \\
\hline $\begin{array}{l}\text { EP/APP/FS } 40 \% \\
\text { (before burning) }\end{array}$ & 63.19 & 13.20 & 19.54 & 2.61 & 1.45 \\
\hline $\begin{array}{c}\text { EP/APP/FS } 40 \% \\
\text { (after burning) }\end{array}$ & 41.95 & 11.42 & 32.17 & 12.13 & 2.33 \\
\hline
\end{tabular}

\subsection{Char analysis}

Raman spectroscopy is used to determine the vibrational and rotational modes of a crystal lattice or molecule. When light hits a molecule and interacts with the electronic 
cloud and molecular bonds within the molecule, it causes a Raman effect, that is, when an excited molecule releases a photon, it returns to a vibrational or rotational mode that is different from the ground state. The energy difference between the ground state and the new state causes the frequency of the released photon to be different from the excitation wavelength of the light, which means its spectrum carries the characteristics of the material in frequency, intensity, and polarization. Therefore, Raman spectroscopy can be used to determine the compositions of a substance.

This study used Raman spectroscopy to analyze the char of the EP/APP/FS composites, which were left in a high-temperature environment $\left(600{ }^{\circ} \mathrm{C}\right)$ for 1 and $5 \mathrm{~min}$. The Raman spectrum was observed for changes in the disorder (D)-band and graphitic (G)-band [19-20]. The D-band, which is located at $1350 \mathrm{~cm}-1$, represents an irregular sp3 structure formed by linear carbon chains. After being burned, it becomes char, turning from the D-band into the G-band. The G-band is located at $1580 \mathrm{~cm}-1$ and represents an $\mathrm{sp} 2$ structure formed by hexagonal carbon rings, the structure of graphite. The presence of a larger number of G-bands indicates an abundance of char, that is, a favorable carbonized state (because char is mainly composed of hexagonal carbon rings). Dividing the area of D-band by that of the G-band produces a D:G ratio; smaller ratios indicate a larger abundance of graphite, which indicates that more char that is formed (Table 7).

Figure 8 and Figure 9 present the changes in the D-band and G-band of EP/APP/FS $10 \%$ and $\mathrm{EP} / \mathrm{APP} / \mathrm{FS} 40 \%$. According to the analytic results presented in Table 7, both low and high concentrations increased the amount of char. This indicates that the addition of the composite flame retardant effectively increased the amount of char that was formed in the burning process, which made the material more difficult to burn, and that the flame retardant effect was greater at a higher concentration.

$$
\text { D-band G-band }
$$
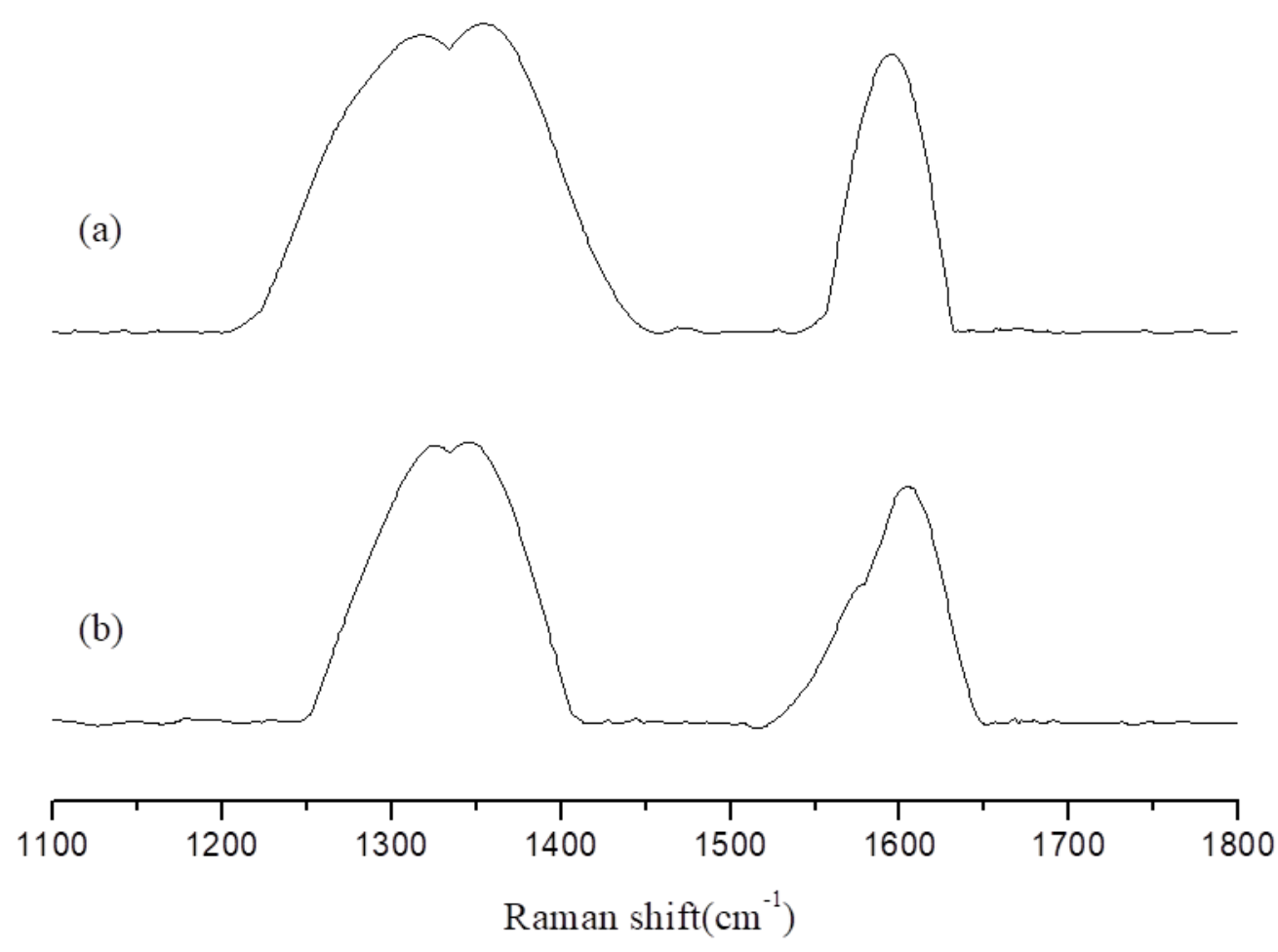

Figure 8 The Raman spectra of char products from Epoxy/APP/FS $10 \%$ at $800^{\circ} \mathrm{C}$ (a) $1 \mathrm{~min}$ (b) $5 \mathrm{~min}$. 


\begin{tabular}{lllll}
\hline & & D-band & G-band & \multirow{2}{*}{ D/G } \\
\cline { 3 - 4 } & & $1350 \mathrm{~cm}^{-1}$ & $1850 \mathrm{~cm}^{-1}$ & \\
\hline \multirow{2}{*}{ EP/APP/FS 10\% } & $1 \mathrm{~min}$ & 723254 & 220353 & 3.282 \\
& $5 \mathrm{~min}$ & 106075 & 106075 & 2.019 \\
EP/APP/FS 40\% & $1 \mathrm{~min}$ & 514002 & 414064 & 1.241 \\
& $5 \mathrm{~min}$ & 176812 & 322428 & 0.548 \\
\hline
\end{tabular}

\section{Conclusions}

This study addressed the problems that EP that is highly flammable and that it does not self-extinguish once on fire. The solution proposed in this study was the introduction of a composite flame retardant comprising both APP and FS which was proven to lower the flammability of the polymeric base material and make it more difficult to burn. The inclusion of FS can lower the consumption of APP and is also a suitable use for a waste material. Therefore, it is a cost-efficient and environmentally friendly approach that can serve as an element in a circular economy. When the proportion of the APP/FS flame retardant in EP was raised to $40 \%$, it effectively raised CY to $36.07 \mathrm{wt}$ \%, IPDT to $1143.1^{\circ} \mathrm{C}$, UL94 classification to V-0, and LOI to $36 \%$, thus turning EP from a flammable material into a fireproof material. These results indicate that adding the APP/FS flame retardant to $\mathrm{EP}$ to form an EP/APP/FS composite increases the thermal stability of the material and reduces its flammability considerably.

Author Contributions: Conceptualization, C.-L.C.; Methodology \& Software, M.-Y.S.; Validation,C.-Y.Y.and C.-L.C.; Formal Analysis, C.-L.C.; Investigation, C.-Y.Y.; Data Curation,Writing - Original Draft Preparation, Writing - Review \& Editing, C.-L.C. All authors have read and agreed to the published version of the manuscript.

Funding: The authors would like to express their appreciation to the National Science Council of the Republic of China for financial support of this study under Grant MOST 109-2221-E-241 -003 -MY3

Data Availability Statement: Not applicable.

Conflicts of Interest: The authors declare no conflict of interest.

\section{References}

1. Xiang, Q.; Xiao. F. Applications of epoxy materials in pavement engineering. Constr Build Mater. 2020, 235, 117529.

2. Jian, R.K.; Ai, Y.F.; Xia, L.; Zhao, L.J.; Zhao, H.B. Single component phosphamide-based intumescent flame retardant with potential reactivity towards low flammability and smoke epoxy resins. J. Hazard. Mater. 2019, 371, 529-539.

3. Li, J.; Wang, H.; Li, S. A novel phosphorus-silicon containing epoxy resin with enhanced thermal stability, flame retardancy and mechanical properties. Polym. Degrad. Stab. 2019, 164, 36-45.

4. Zhang, W.; Fina, A.; Ferraro, G.; Yang, R. FTIR and GCMS analysis of epoxy resin decomposition products feeding the flame during UL 94 standard flammability test. Application to the understanding of the blowing-out effect in epoxy/polyhedral silsesquioxane formulations. J Anal Appl Pyrolysis 2018, 135, 271-280.

5. Paul, S.; Pal, A.; Choudhury, A.R.; Bodhank, S.; Balla, V.K.; Sinha, A.; Das, M. Effect of trace elements on the sintering effect of fish scale derived hydroxyapatite and its bioactivity. Ceram. Int. 2017, 43, 15678-15684.

6. Muhammad, N.;Gao, Y.; Iqbal, E.; Ahmad, P.; Ge, R.; Nishan, U.; Rahim, A.; Gonfa, G.; Ullah, Z. Extraction of biocompatible hydroxyapatite from fish scales using novel approach of ionic liquid pretreatment. Sep. Purif. Technol. 2016, 161, 129-135.

7. Alina, S.; Justyna, K.; Fish scales as a biocomposite of collagen and calcium salts. Key Eng. Mater. 2014, 587, 185-190。

8. Guo, W.; Liu, J.; Zhang, P.; Song, L.; Wang, X.; Hu Y. Multi-functional hydroxyapatite/polyvinyl alcohol composite aerogels with self-cleaning, superior fire resistance and low thermal conductivity. Compos Sci Technol 2018, 158, 128-136. 
9. Gou, X.; Zhao, X.; Singh, S.; Qiao, D. Tri-pyrolysis: A thermo-kinetic characterisation of polyethylene, cornstalk, and anthracite coal using TGA-FTIR analysis. Fuel 2019, 252, 93-402.

10. Xiang, S.; Feng, L.; Bin, X.; Li, G.; Chen, X. Evaluation of PLA content in PLA/PBAT blends using TGA. Polym. Test. 2020, 81, 106211.

11. Laxmi., Khan S.; Zafar, F.; Kareem, A.; Nami, S.A.A.; Alam, M.;Nishat, N. Development of coordination polyureas derived from amine terminated polyurea and metal ions having ' $\mathrm{d} 5$ ', ' $\mathrm{d} 7$ ', ' $\mathrm{d} 8$ ' and 'd10' orbitals: From synthesis to applications. Spectrochim Acta A Mol. Biomol. Spectrosc. 2019, 219, 552-568.

12. Laxmi., Khan S.; Kareem, A.; Zafar, F.; Nishat, N. Synthesis, vibrational spectrometry and thermal characterizations of coordination polymers derived from divalent metal ions and hydroxyl terminated polyurethane as ligand. Spectrochim Acta A Mol. Biomol. Spectrosc. 2018, 188, 400-410.

13. Hsieh, W.H.; Cheng, W.T.; Chen, L.C.; Lin, S.Y. Non-isothermal dehydration kinetic study of aspartame hemihydrate using DSC, TGA and DSC-FTIR microspectroscopy. Asian J. Pharm. 2018, 13, 212-219.

14. Sun, J.; Li, L.; Li, J. Effects of furan-phosphamide derivative on flame retardancy and crystallization behaviors of poly(lactic acid). Chin. J. Chem. Eng. 2019, 369, 150-160.

15. Wang, S.; Wang, X.; Wang, X.; Li, H.; Sun, J.; Sun, W.; Yao, Y.; Gu, X.; Zhang, S. Surface coated rigid polyurethane foam with durable flame retardancy and improved mechanical property. Chin. J. Chem. Eng. 2020, 385, 123755.

16. Wang, J.; Ma, C.; Wang, P.; Qiu, S.; Cai, W.; Hu, Y. Ultra-low phosphorus loading to achieve the superior flame retardancy of epoxy resin. Polym. Degrad. Stab. 2018, 149, 119-128.

17. Zhang, T.; Tao, Y.; Zhou, F.; Sheng, H.; Qiu, S.; Ma, C.; Hu, Y. Synthesis of a hyperbranched phosphorus-containing polyurethane as char forming agent combined with ammonium polyphosphate for reducing fire hazard of polypropylene. Polym. Degrad. Stab. 2019, 165, 207-219.

18. Guo, W.; Wang, X.; Zhang, P.; Liu, J.; Lei, S.; Hu, Y. Nano-fibrillated cellulose-hydroxyapatite based composite foams with excellent fire resistance. Carbohydr. Polym.2018, 195, 71-78.

19. Alttar, N.A.; Kopf, L.; Flavin. K; Kennedy, E.; Giordani, S.; Rice, J.H. Surface-enhanced Raman scattering spectra of radial breathing and $\mathrm{G}$ band modes in functionalised nanotubes. Chem. Phys. Lett. 2013, 568-569, 95-100.

20. Xu, J.; Liu, J.; Zhang, X.; Ling, P.; Xu, K.; He, L.; Su, S.; Wang, Y.;Hu, S.;Xiang, J. Chemical imaging of coal in micro-scale with Raman mapping technology. Fuel 2020, 264, 116826. 